then that we had here a tumour which originated in, and had absorbed the whole of the lower part of, the iris. Microscopically this tumour, examined quite fresh, proved to be composed of closely-packed spindle-shaped cells and pigment masses of irregular shape and distribution. The cells possessed a large, well-defined nucleus, with a highly refractive nucleolus, round which nucleolus there were a number of fine granules. The nucleus filled up nearly the whole of the oval cell-body, from the two poles of which fine tapering filaments proceeded, having their terminal portions divided into finer branchlets. (See Fig. 1.)
Fia. 1.

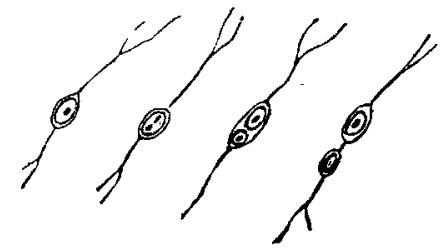

FIG. 2.

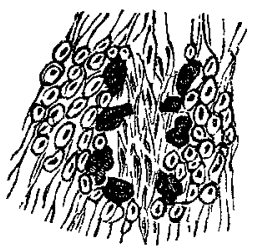

Fig. 1.-Isolated tumour-cells, showing cell growth. $\times 300$.

Fig. 2.- Section of tumour,"showing sarcoma-cells and pigment masses enclosing a mass of organic muscle-cells, $\times 300$.

With the view of making a more minute examination, one-half of the eye was hardened in Müller's fluid, and the following results were arrived at as regards the structure, the etiology, and the growth of the tumour.

Structure.-Thin sections at different regions of the tumour showed it to be composed of two parts. The one less trans. parent consisted of the above-described spindle-cells, closely packed in rows, running in different directions, some vertical, others slanting, with hardly any intercellular substance; the other more transparent, forming round or oblong islets surrounded everywhere by the spindle-cells, from which, however, in most sections they were separated by a layer of pigment masses. (See Fig. 2) These islets proved to be cells of organic muscle, their rod-like nuclei, their size and general outline, distinguishing them well from the sarcoma elements, and they were evidently parts of the original muscular tissue of the iris, around which the sarcoma had developed. Besides these elements there were small bloodzessels seen in all parts of the tumour, and pigment masses, of irregular shape, resisting all reagents, even sulphuric acid. These pigment conglomerations, not being contained in cells, were evidently nothing but the remains of the extravasated blood due to the repeated hæmorrhages which had been noticed during the progress of the case, and I have hence considered the tumour, in spite of the pigment colouration, a simple non-melanotic sarcoma.

Where the tumour had abutted against the cornea, the microscope showed the disappearance of the posterior epithelial layer of the cornea and a fatty degeneration of the latter, fat-granules filling up the interior of the corneacorpuscles, and lying also free in the intralamellar spaces.

Etiology. - The fact that masses of muscle-cells were found intact in the midst of the tumour indicated that the tumour originated in the intermuscular tissue, and sections made close to the posterior pigment-lajer of the iris, where the tumour was still found in the infancy of its development, left no doubt as to the correctness of this view; for here (see Figs. 3 and 4) the layers of muscle-cells

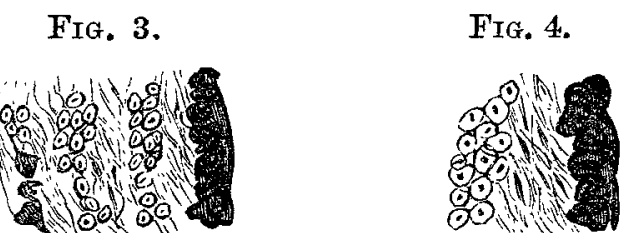

Fig. 3.-Seetion of tumour elose to pigment layer of iris, showing aggregation of nuclei between muscle-cells. $\times 300$.

Fig. 4.-Part of the same magnified 450 times.

of the iris were separated by masses of nuclei, of the same size and appearance as the nuclei of the sarcoma-cells. Fach nucleus showed a distinct highly refractive nucleolus, and while in some of these heaps the nuclei were closely packed, in others they were separated from each other by a finely granular matrix. The cellular elements of the connective tissue of the iris (starlike cells and lymphoid cells) were seen in a few places, but showed no traces of proliferation.
From this description, it is more than probable that the tumour originated in nuclei which appeared in the intermuscular connective tissue; that these nuclei proliferated, became surrounded by a granular matrix, and eventually formed the spindle-cells. This view derives further support from the observations of Sokolow (Virchow's Archiv, 1873, liii., p. 321) on the development of spindle-celled sarcoma in striped muscular tissue, in which he describes the sarcomacells as springing from the intra-muscular nuclei, and also from an examination of a primary round-celled sarcoma in the muscular tissue of the heart (which I bad an opportunity of observing, and an account of which I hope shortly to publish), where both Mr. Jones (pathologist to the infirmary) and myself could distinctly trace the origin of the tumour to free nuclei appearing in the inter-muscular connective tissue.

Growth-Though the preceding observation showed the development of the sarcoma from free nuclei, a glance at some of the isolated sarcoma-cells showed that its growth was chiefly due to a process of cell-division, for the different stages of this process were readily discerned in the cells, there being cells with two nucleoli, others with two nuclei, and others where two fully formed cells were united by a fine filament (see Fig. 1).

Manchester.

\section{CASE OF TRAUMATIC TETANUS TREATED BY CHLORAL HYDRATE AND CANNABIS INDICA ; \\ DEATH AFTER TWENTY-ONE DAYS.}

BY SURGEON J. BUTLER HAMILTON, M.D., MEDICAL STAPF, FOBT PITT, CHATHAM.

SAPPER W-, a powerfully-built young man, aged twenty-five, was admitted to Fort Pitt Hospital on the 16th of November, suffering from compound comminuted fractures of the last two joints of the index and middle fingers of the left hand. He stated that he was trying to cross the line when partly intoxicated, and, seeing a train approaching, made a run to pass before it, but tripping, he fell just in front of the engine, the wheels of which passed over the two fingers above mentioned. This statement was doubted from the first, as it seemed quite impossible for the "index" and "middle" fingers to be so injured and yet that the "third" should escape entirely; thus from a medico-legal point of view the case is one of importance. It afterwards was proved by the evidence of the engine-driver and some platelayers who saw the occurrence, that he actually sat by the side of the line till the train approached, when with the greatest deliberation he placed his left hand on the rail, and sustained the injuries for which he was admitted. It will be perceived by anjone placing his fingers on the edge of the table, that if the first two fingers were smashed as far as the first joint, the third could not escape unless it were doubled under, and as the object in view no doubt was to get his discharge from the service, he wilfully mutilated himself. It is interesting to record that he stated he felt no pain whatever when the injury was inflicted, " merely a little numb."

The injured parts were amputated the same evening by Surgeon-Major Fox, R.E.

The case progressed favourably from the 16th of Nov. till the 26th, when the stumps took on rather unhealthy action, and the flaps slonghed.

On the 30th Nov. he was attacked by slight twitchings of the arm with a stiffness about the neck and face, but unfortunately made no remark on the subject, though seen during the day by no fewer than four medical officers at various hours.

On the 1st of Dec. the tetanic symptoms becoming more pronounced were at once recognised, when the following was his condition :-Well-marked trismus, jaw almost completely closed; sense of fulness in throat; twitchings of left arm, extending from stumps of fingers to armpits; skin hot; temperature $100 \cdot 2^{\circ}$; pulse 100 , and rather hard; tongue foul. Moved into a separate ward; special at- 
tendants told off to look after the case. To have at once five grains of calomel with two drops of croton oil, and as soon as the bowels are moved, thirty grains of chloral hydrate in a draught every fourth hour. In the evening he was rather better; bowels freely open; spasms had not extended beyond the muscles of jaw. Temperature $100^{\circ}$; pulse 94. To have twenty grains of chloral hydrate every second hour while awake.

On the 2nd of December he is noted as being much in the same condition; trismus well marked, pulse 100, and temperature $99 \cdot 2^{\circ}$. To have twenty grains of chloral every fourth hour, poultice to stumps, and for diet as much milk and beef-tea as he can consume.

On Dec. 3rd he is noted as being "decidedly worse"; pulse 112 ; temperature $99^{\circ}$; mouth firmly closed; cannot separate teeth; general rigidity of muscles of trunk, with severe spasms of back and chest coming on at short intervals; twitchings of arm less complained of ; bowels constipated. To take two scruples of compound jalap powder and two grains of calomel at once; to have twenty grains of chloral hydrate every second hour, with a grain of cannabis indica every intervening hour while awake. An unlimited supply of beef-tea, jelly, and milk was ordered, of which he takes large quantities, sucking them in between his teeth.

On Dec. 4th (fifth day) he continued much in the same condition, but as some diplopia was present, doubtless caused by the cannabis, the doses of it and of the chloral were given at intervals of an alternate hour and a half, instead of every alternate hour. Pulse 104; temperature $98 \cdot 4^{\circ}$.

Sixth day.-Spasms continue at short intervals, but not so severe. Rigidity of trunk continues. Pulse 94; temperature $984^{\circ}$. Bowels constipated. Ordered two grains of calomel and one drop of croton oil ; the cannabis to be reduced to half a grain every third hour, with twenty grains of chloral in the alternate hour and a half.

Seventh day.-In much the same state. Palse 86 ; tempezature $99 \cdot 2^{\circ}$. Continue treatment.

Eighth day.-Much the same report. On the whole a little better. Spasms not so frequent; rigidity of body in statu quo; takes plenty of nourishment. To continue cannabis and chloral as before.

Ninth day.-No change. Pulse 76 ; temperature $99 \cdot 4^{\circ}$

Tenth day.-Pains in back more severe, and a decided tendency to opisthotonos; trismus extreme. Pulse 88 ; temperature $98 \cdot 2^{\circ}$. Bowels not open. Repeat calomel and croton oil, and to have one ounce of brandy every third hour while awake.

Eleventh day.-Worse last night; marked opisthotonos, lasting for ten minutes at a time. Cannabis increased to one grain, twenty grains of chloral as before, a dose of each to be taken every alternate hour and a half. Pulse 108, full and soft ; temperature $998^{\circ}$.

Twelfth day.-Decidedly worse; spasms increasing in intensity, with occasional fits of well-marked opisthotonos. Temperature $98 \cdot 2^{\circ}$; pulse 96 . To continue chloral and cannabis as before, and given a hypodermic injection of three grains of chloral in twenty drops of water over the diaphragm on right side. In the evening he stated he felt easier, and was given a second injection of five grains of chloral.

Thirteenth day.-The report is more favourable. Slept fairly during the night; spasms much fewer and less tonic; able to separate teeth nearly half an inch; rigidity of muscles of trunk continues as before. Pulse 104; temperature $98.4^{\circ}$; skin moist; petechial rash on chest and abdomen. To continue the cannabis and chloral, and to have a hypodermic injection of five grains of chloral in twenty drops of water morning and evening.

Fourteenth day.-Worse. Spasms very troublesome during the night. Temperature $100^{\circ}$; pulse 96 . To continue chloral and cannabis, and to have hypodermic injections of seven grains of chloral night and morning; taking large quantities of nourishment-namely, two eggs, four pints of beef-tea (boiled down to half), three ounces of sherry, four ounces of brandy, two pints of milk, and chicken diet made into broth.

Fifteenth day.-Bad night. Spasms general and troublesome. Pulse 104; temperature $1002^{\circ}$. To continue chloral and cannabis, also hypodermic injections.

Sixteenth day.-Passed a good night; slept during the greater portion. Pulse 112 ; temperature $99 \cdot 2^{\circ}$. Continue treatment and to be allowed to smoke. Mr. Henry Power kindly saw the case with me, and made an ophthalmoscopic examination of the fundi with the following results:"Slight optic neuritis of both eyes; vessels slightly engorged; discs pinkish, margins rather hazy ; lower margin of right one apparently slightly thickened, the vessels making a sharp curve forwards over it." The above condition is, no doubt, the result of the general state of irritation of the spinal cord.

Seventeenth day.-Slept fairly till 4 A.Mr., then woke and suffered severely from spasms of abdominal muscles, the body being almost in a state of emprosthotonos. Temperature $99^{\circ}$; pulse 104 . Continue chloral and cannabis internally as before, and increase the hypodermic injection of chloral to ten grains morning and evening. Still takes nourishment and stimulants in large quantities.

Eighteenth day.-Slept well ; woke at 4 A.M., since when he has been in much pain; body perfectly rigid; emprosthotonos passed off. Pulse 112; temperature $100^{\circ}$. Bowels constipated. Repeat croton oil and calomel, and continue treatment.

Nineteenth day.-Slept nearly all night; a few slight spasms this morning; trismus a little relaxed. Temperature $100 \cdot 2^{\circ}$; pulse 124 . Continue treatment.

Twentieth day.-Fair night; slept well. Spasms came on at 7 A.m., but not badly. Diplopia quite passed off. Temperature $100 \cdot 6^{\circ}$; pulse 120 , rather weak. Continue treatment.

Twenty-first day.-Died quite suddenly this morning at 6.30 A.Mr. The following is the report of the orderly on duty :-Passed a rather restless night. At 6.20 asked for a little brandy and water, and while in the act of drinking was attacked by a most violent spasm of the whole of the muscles of the trunk, became insensible, and when seen in a few minutes by Surgeon-Major Slaughter was moribund.

No post-mortem examination was made, in accordance with the wishes of his friends, but the following points were noted:-Features quite calm; body extremely blanched; presents the appearance of a man who had been bled to death; scrotum much swollen and cdematous; rigor mortis extreme; general emaciation.

The chief points of interest in connexion with the above case are-first, the cause of the injury. Cases of selfmutilation among soldiers are not rare, but the cool determination displayed by this man is unexampled. He was deseribed by the platelayers as deliberately sitting waiting for the train, and, calculating how much would be necessary to effect his purpose, must have bent his third finger to save it. The next point of importance to be remarked is the enormous amount of chloral and cannabis indica he took without once exhibiting any symptoms of narcotism. I calculate that by the mouth he consumed nearly five ounces of chloral and two drachms of cannabis indica, while he had nearly two drachms of chloral injected into the cellular tissue. The long duration of the ease (twenty-one days) was no doubt owing to the power of the drugs over the spasmodic condition of the muscles, combined with the extraordinary facility with which he was able to take enormous quantities or nourishment. His intellect was clear all through, and ten minutes before his death he was perfectly sensible. The treatment by the hypodermic method seemed to be the most efficacious; by throwing the injection into the cellular tissue over the part most troubled by spasm, relief was given within an hour or so. Mr. Power's ophthalmoscopic examination is also valuable as showing the general neuritic condition of the optic nerves. It will be remembered that, throughout the case, the temperature never rose very high, notwithstanding the constant state of muscular tension. One other fact is worthy of note. Beneath Fort Pitt runs the tunnel of the London, Chatham, and Dover Railway, and when trains pass through, the vibration can be felt (but not very much) throughout the hospital. One of the wardmasters who slept in the room underneath the ward in which this case was lying assured me that every time a train passed through the tunnel the vibration seemed to bring on the spasms, and he could distinctly hear the bed shaking overhead for several minutes.

The treatment of tetanus by chloral (certainly, judging by this case) holds out some small hopes of its being the most likely method of obtaining a favourable result.

Chatham. 